\title{
Unsettling aging futures: challenging colonial-normativity in social gerontology
}

\author{
BY MAY CHAZAN*
}

\begin{abstract}
This article explores the stories of two women activists, both in their mid to later lives, both grandmothers, and both Indigenous to what is now Canada. Both women participated in intergenerational storytelling research in 2017, as part of a multiyear (2016-2020) oral history project. The article brings their stories into dialogue with critical writings on "successful aging" discourse and notions of "happy aging futures" while also reaching beyond gerontology to examine related work by Indigenous scholars in other fields. In doing so, it challenges the ongoing colonialnormativity of interrelated gerontological conceptualizations of generativity and futurity, building on existing efforts to queer and crip these concepts. It ultimately contributes to efforts to understand complexity among multiple aging experiences, opening possibilities of livable and positive futures among those who do not identify with dominant images of wealthy, physically fit older couples with grandchildren.
\end{abstract}

Keywords: colonial-normativity, crip, futurity, generativity, Indigenous, queer, successful aging.

* May Chazan, Department of Gender \& Women's Studies, Trent University, Peterborough, Ontario, Canada 
International Journal of Ageing and Later Life

\begin{abstract}
"I want to welcome laughter into the room. She is very powerful. She brings us together and sustains us into the future." (Elder Audrey Kewaquom-Caskanette, research interview, 2017)

"That moment when I realized I am an ancestor - that was when I understood what sustains me, my work. What I do matters for seven generations to come. That moment was a game-changer." (Tasha Beeds, research interview, 2017)
\end{abstract}

This article foregrounds the stories of two Indigenous women activists: Elder Audrey Kewaquom-Caskanette and Tasha Beeds, both in their mid to later lives, and both grandmothers. Elder Caskanette introduces herself as Anishinaabek from Saugeen on the Bruce Peninsula (in what is now Ontario, Canada). Beeds introduces herself as Nehiyaw (Cree), of the Bear Clan, from Treaty 6 territory (in what is now Saskatchewan, Canada). Both women participated in intergenerational storytelling research, which I facilitated at Trent University in Nogojiwanong ${ }^{1}$ (Peterborough, Ontario) in 2017, as part of a multiyear (2016-2020) oral history project. In this article, I bring their stories into dialogue with critical social gerontological writings on aging futures while also reaching beyond scholarship on aging to examine related work by Indigenous scholars in other fields, to explore how close listening to Indigenous perspectives might challenge and extend the interrelated concepts of generativity and futurity as these are typically understood within gerontology.

I build conceptually on Sandberg's and Marshall's (2017) project of queering/cripping ${ }^{2}$ aging futures, which is rooted in a critique of

\footnotetext{
${ }^{1}$ Nogojiwanong in Anishinaabemowin means "the place at the foot of the rapids." This is the original name for the region $150 \mathrm{~km}$ northeast of the major urban centre of Toronto; it contains the midsized city of Peterborough. This territory is governed by colonial treaties, Treaty 20 and the Williams Treaties, although these treaty relationships have repeatedly been violated by settlers (non-Indigenous people), corporations, and colonial governments (Gidigaa Migizi (Williams) 2018; Taylor \& Dokis 2015).

2 By 'queering,' I am referring to an analysis that aims to critically interrogate the workings of hetero- and cis-normativity, drawing on what is widely known as 'queer theory.' The use of the word 'queer' is a reclamation of a derogatory slur, recognizing the existence of queer cultures and identities, as well as the knowledge contributions and epistemological interventions offered by people occupying multiple, nonnormative subject positions with respect to gender and sexuality. By 'cripping,' I am referring to an analysis that similarly interrogates the workings of ableism and norms that privilege able-bodiedness/able-mindedness, drawing on critical disability perspectives and what is known as 'crip theory.' Like 'queer,' the use
} 
dominant "successful aging" discourse. ${ }^{3}$ Central to their argument is that "successful aging is not just about what one does in the here and now, but contains an imperative for the future - an association of aging with possible futures" (Sandberg \& Marshall 2017: 3). Their project of queering and cripping seeks to disrupt simplistic narratives of "happy aging futures," which are shaped by the intertwining of compulsory heteronormativity and compulsory able-bodiedness and able-mindedness, ${ }^{4}$ as represented by widely circulated images of affluent, physically fit, hetero (and I would add white) couples, leisurely interacting with their grandchildren. It calls into question the ways that "expectations of a good later life and happy aging futures adhere to some bodies and subjectivities over others" (Sandberg \& Marshall 2017: 2).

At the core of their critique is that successful aging discourse presumes that success in later life depends on a particular conception of generativity as an individual's connection to future life. ${ }^{5}$ The assumed corollary in this socially constructed success-failure binary is that a lack of generativity is a sign of failed aging, with the result being a lack of possible futurity. Specifically, Sandberg and Marshall critique this notion of generativity

of the word 'crip' is a reclamation of the derogatory word 'cripple,' recognizing and valuing the existence and contributions of crip cultures and identities. Both queer and crip theories seek to challenge objectifying gazes turned upon people occupying nonnormative subject positions within dominant systems of power, and both critically investigate power systems as intersecting and overlapping (i.e. recognizing that heteronormativity/ableism interact with each other and with patriarchy, capitalism, white supremacy, colonialism, and so on, to create multiple subject positions and diverse experiences privilege and oppression). See Kafer (2013) for further discussion.

${ }^{3}$ Sandberg and Marshall (2017) provide an excellent review of literature that critiques "successful aging" discourse and related discourses of active and healthy aging. See also The Gerontologist 2014 (Vol. 55, Issue 1), which focuses on related critique and commentary.

${ }^{4}$ See also Kafer (2013) on the ways in which compulsory heteronormativity and compulsory able-bodiedness/able-mindedness intertwine.

${ }^{5}$ Hostetler (2009) offers a detailed review of generativity, tracing the concept back to Erikson's (1963) work, which popularized it as "establishing and guiding the next generation" and/or investing in projects that "outlive the self," anchoring the individual lifecourse in linear conceptions of both lifetime and sociohistorical time. In the project of queering generativity, Hostetler articulates definitions of "gay generativity" within and outside of the normative frame, suggesting that generativity, defined as "an individual's link to the future," has yet to be commonly applied to conceptions of LGBTQ2IA+ aging because it remains deeply rooted in heteronormative familial and reproductive narratives. 
International Journal of Ageing and Later Life

as dependent on heterosexual reproduction. They explain: "depictions of older people with children and grandchildren suggest more than their reproductive success in the present - they are a frequent trope in establishing generativity and the extension of life into the future" (Sandberg \& Marshall 2017: 4). And, this consistent "imagery of reproductive success" presupposes that it is "(hetero)kinship that makes later life meaningful and positive" (Sandberg \& Marshall 2017: 3). At the same time, they argue that this conceptualization of generative success requires older adults to have a high level of physical and mental ableness, to enable these familial relationships without the burden of older people being dependent, and to prevent the pain and sorrow supposedly connected to disability and/or memory loss (see also Grande 2018). In particular, success narratives assume a freedom from dementia, which can be understood as a disruption to generative connections to future life, by way of stunting memories and thus relationships: "If the success of hetero-aging futures lies partly in its links to generativity, then dementia - through loss of memory threatens to disrupt that generativity and represents as such a form of queer crip temporality" (Sandberg \& Marshall 2017: 5).

From this complex argument, they set out to simultaneously queer and crip aging futures, sustaining a critique of the concepts of generativity and futurity within gerontological writings. This work, which aims to illuminate a diversity of aging experiences, builds on a growing body of scholarship at the intersection of gerontology and feminist, queer, and crip studies. Indeed, Sandberg and Marshall contribute to a wider project of making legible a multiplicity of positive futures - futures among groups whose lives Western ${ }^{6}$ societies do not typically value as worth preserving into old age. This project of queering and cripping aging futures is thus imperative in making spaces for lives lived outside of constricting success-versus-failure binaries (for more reflections on livable

${ }^{6}$ Sandberg and Marshall (2017) refer to "Western" societies in their analysis. This language is contested, although to some extent this is a useful term. More clearly, however, I believe that they are referring to capitalist/settler colonial societies, in which the intertwining dominant systems of capitalist, colonial, heteropatriarchal, white supremacist power tend to value certain lives over others. LGBTQ2IA+ people (i.e. lesbian, gay, trans, queer, two-spirit, intersex, asexual, and people of other nonnormative sexual and gender expressions) and people living with disabilities are among those who are marginalized vis-à-vis these systems. 
crip and/or queer futures, see Fabbre 2014; Jones 2011; Rice et al. 2017; Shepherd 2016).

What this queering/cripping intervention does not interrogate, however, is the enduring whiteness and colonial-normativity of dominant narratives on aging and generativity concepts. Such analyses remain sparse in much critical gerontology (Chazan 2018; Grande 2018; Ranzijn 2010). Indeed, Quechua scholar Sandy Grande (2018) has recently offered an important analysis toward a critical Indigenous counter-narrative of aging (i.e. an Indigenous perspective on aging that challenges dominant narratives on aging). Elsewhere, scholars are also seeking to include Indigenous (and other "marginalized" or "diverse") perspectives and Indigenous-focused "data" to gerontology research, in what Braun et al. refer to as the "growing field of Indigenous gerontology" (2014: 125). What is important, from the perspective of this article, is that many contributions to this subfield do not explicitly critique the colonial-normativity of core concepts or assumptions within gerontology (e.g. Lewis \& Allen 2017; Warburton 2014). While conversations among Indigenous and decolonial scholars outside of gerontology could assist in retheorizing concepts of generativity, aging, and futurities (e.g. Belcourt \& Roberts 2016; Boissoneau 2016; Nixon 2016; Peek 2014; sy 2016, 2018; Tallbear 2016), gerontologists have yet to fully engage with much of this work. Thus, in this article I extend Sandberg's and Marshall's important work - unsettling the project of queering/cripping aging futures by engaging centrally with Indigenous and decolonial perspectives. ${ }^{7}$

To do so, I draw on digital storytelling research carried out in 2017 with a multiage group of activists, students, and researchers in Nogojiwanong. This project, "Stories of Resistance, Resurgence, and Resilience in Nogojiwanong," aims to create an oral history of Nogojiwanong's diverse

\footnotetext{
${ }^{7}$ It is important to clarify the approach that I am hoping not to take in this article: as a white, settler (non-Indigenous) researcher, I do not view this as "doing research on" Indigenous groups for the purposes of either adding diversity (in a "add and stir" fashion) to a white-centric field or as reinforcing existing concepts, frameworks, or assumptions. I am instead exploring some of the work of Indigenous scholars outside of gerontology, and offering certain stories generously shared with me in my own research, with a hope that this might bring different ways of thinking about core gerontological concepts. I am asking whether and how my own work and that of others engaged in these conversations might grow through close reading of and listening to Indigenous perspectives.
} 
International Journal of Ageing and Later Life

and lesser-known activisms ${ }^{8}$ through a series of annual, intergenerational ${ }^{9}$ storytelling and media creation workshops. Informed by decolonial, feminist, and queer storytelling methodologies (Cunsolo Willox et al. 2012; Rice et al. 2015; Sium \& Ritskes 2013), the project centers the experiences, stories, and knowledges of queer activists, Indigenous activists, activists living with disabilities, and activists of color. As such, it offers a window into stories that tend to be eclipsed within successful aging discourse, or which are assumed to fall within the "failed" side of this imagined dichotomy. From this project, I focus specifically on Caskanette's and Beeds' stories in part because they are thematically illustrative of many stories offered through this project and in part because of these storytellers' explicit identifications as grandmothers offer an entry to critically explore assumptions about (hetero-reproductive) generativity as a part of a happy aging futures discourse. Their words, contextualized within the writings of Indigenous scholars from outside of gerontology, allow me to critically explore how aging might be conceptualized outside of colonial-normative narratives and worldviews.

Ultimately, I argue that the project of queering/cripping aging futures, as critical as it is, needs to be unsettled through ongoing engagement

\footnotetext{
${ }^{8}$ I use the plural "activisms" to refer to diverse social change practices, including protest/ rally as well as arts-based interventions, land-based practices, performance, cultural resurgence, creativity, survivance, refusal, ceremony, advocacy, and so on. This focus on aging and activism is not intended to depict another version of active or healthy aging; nor does it align neatly with research on voluntarism in older adults and its association with health, civic engagement, and/or generativity (Morrow-Howell, Hong, \& Tang 2009; Warburton 2014). This focus on storying activisms pushes back against narratives of both "aging as decline" and "aging well." Understanding how people work for change in creative ways across the lifecourse offers a number of alternative stories about aging resistantly and resiliently in the face of ongoing oppressions (see Chazan 2018).

${ }^{9}$ By intergenerational storytelling, I am referring to coproducing knowledge through conversations among people of many different ages, who hold contrasting sociohistorical perspectives and varied narrative timelines. This approach to intergenerationality seeks to expand and challenge conventional ideas of intergenerational knowledge transmission as a passing down of preformed knowledge from elder to younger, instead exploring knowledge as coproduced in a multidirectional exchange across age. While "intergenerationality" is sometimes assumed to be inherently "good" (i.e. healing, transformative) or necessarily divisive (as in "generation gap"), this project interrogates whether and how participants' ages are significant points of connection and/or struggle.
} 
with critical decolonial and Indigenous perspectives; by "unsettling," I am referring to an analysis aimed at revealing and destabilizing implicit or taken-for-granted colonial assumptions, privileges, and knowledge systems. While I can only offer a partial unsettling in this article, the storytellers who have participated in my project critically challenge the gerontological concepts at the core of successful aging narratives: generativity and futurity. Collectively, the projects of queering/cripping and unsettling aim to open possibilities for livable and complex later-life experiences for many of those currently Othered, abjected, or invisibilized by neoliberal images of carefree, wealthy, fit, white, hetero couples at play with their grandchildren. What follows in this article is: first, I outline my project and its methodology; then, I outline the existing literature to further explain the project of queering/cripping aging futures and I draw in Indigenous scholarship from outside of gerontology as critical intervention into core concepts and assumptions; and finally, I return to the words and stories shared by Caskanette and Beeds, bringing these into conversations with key ideas and interventions outlined from the literature.

\section{Stories of Resistance, Resurgence, and Resilience: Methodology}

As noted, this article draws on stories recorded as part of an ongoing intergenerational activist storytelling project, which centers stories from groups that have historically been, and remain, least valued in academic scholarship and in social gerontology - women and gender diverse people, people who are racialized, Indigenous peoples, people living with disabilities, and people on the LGBTQ2IA+ spectrum (Chazan 2018). Critical storytelling methodologies posit storying as important decolonial, feminist, and queer forms of knowledge production (e.g. Sium \& Ritskes 2013; Zepeda 2014). This approach - facilitating group-based storytelling workshops as a form of research - recognizes that contexts and relationships inform how stories are constructed, shared, circulated, and remembered. Through its attention to particularity, complexity, and relationality, storytelling-as-methodology has the potential to challenge dominant narratives - "successful aging" as one example - and reveal multiple 
International Journal of Ageing and Later Life

counter-narratives. This project combines storytelling workshops with participatory media-creation methodologies to offer participants' direct input into how their stories are shared and circulated (e.g. Loe 2013).

This research was initiated in early 2016, when I was approached by a local activist organization to lead a project documenting a "people's history of activism in Peterborough." I designed the study to capture and analyze key actors' biographical stories of engaging in multiple activisms in this place, taking an explicitly intergenerational approach, to explore dynamics of age and aging within activists' stories and in our storytelling processes. At the time of writing, I have completed three rounds of these local workshops, in 2016, 2017, and 2018 respectively, each paired with a different community organization, recording a total of 40 stories.

In the 2017 research-generation workshop, during which the stories discussed here were recorded, a group of 18 upper-year undergraduate students in a course on activisms at Trent University gathered with 12 community activists (who became the storytellers), plus nine research assistants/facilitators, to share and record their stories of working for change and their experiences of activist aging in Nogojiwanong. Through existing relationships with me or a member of my research team, activist storytellers of different ages (20s through $80 \mathrm{~s}$ ), abilities, and backgrounds were invited to participate in interviews, circle conversations, and small group discussions. Students, acting as interviewers, asked storytellers: what drew you into social change work in Nogojiwanong, how has your work changed as you have aged, what has sustained you in this work, and what forms does your social change work take now? Students then worked together with storytellers to create short digital stories or media capsules (see www.agingactivisms.org/2017-stories-of-resistance), and the full interviews were archived in the Trent University Library and Archives (see http://digitalcollections.trentu.ca/collections/storiesresistance-resurgence-and-resilience-nogojiwanong-peterborough). In addition to these publicly available materials, the workshop also produced audio recordings of group discussions, participants' written reflections, photographs taken by participants and research assistants, and participant observation notes taken by trained research assistants.

Following these workshops, I have engaged in a process of close reading of all workshop materials and a combination of narrative and thematic analyses. I offer the analysis in this article as the lead researcher on 
this project and as someone who, at the time of the research, had been living, working, and parenting in Nogojiwanong, on Michi Saagiig Anishinaabeg territory, for 4 years. As a settler ${ }^{10}$ newly making home in this community, this research and the relationships fostered through it have contributed immensely not only to extending my thinking around aging, activism, intergenerationality, resistance, and place, but also to shaping my fledgling knowledge of this land, its histories, waters, and peoples. As a (currently) able-bodied, cisgender, white, settler professor, my analysis is necessarily limited: I offer this as a partial and situated analysis, recognizing that there is much that I do not understand and cannot know (Mackey 2016), in a spirit of sharing what was generously shared with me through relationships because I believe this might help challenge certain colonial worldviews and assumptions, which permeate many academic disciplines and systematically privilege some (myself included) and marginalize others. Both Caskanette and Beeds were invited into this project through existing relationships and my relationships with both are ongoing; throughout my analysis, I wish to acknowledge my continued learning through our exchanges and interactions.

While we never directly asked storytellers to reflect on concepts of aging futures, futurities, or generativity, these themes reverberate through how many storied their work for change. What was especially striking in revisiting the entire collection of stories, and in particular in my close reading of the 10 stories offered by Indigenous storytellers of different backgrounds, was the ways in which many discussed collective futurities and their responsibilities to nurture links to future (and past) generations. In doing so, they offered important challenges to the ongoing colonial-normativity within concepts of futurity and generativity as they are typically understood within gerontology. While meaningfully sharing more than a couple of stories from this project is beyond what is possible in an article of this length, and with a caution to readers wishing to generalize what I offer here toward some pan-Indigenous understanding of aging futures, I am choosing to pivot this article around Caskanette's and Beeds' stories because these illustrate many such interventions offered throughout the project. Nevertheless, I contextualize these stories

\footnotetext{
${ }^{10}$ My own roots lie in now-displaced Jewish communities in Eastern Europe, and I grew up
} in Kanien'keha:ka territory, in what is now Montreal (Canada). 
International Journal of Ageing and Later Life

within the scholarship of diverse Indigenous scholars in the section that follows.

\section{Queering, cripping, and unsettling: Conceptual interventions}

Before turning to Caskanette's and Beeds' stories, I would like to further contextualize this analysis within discussions of generativity and futurity at the intersections of queer, crip, feminist, and gerontological studies, and among Indigenous scholars and writers outside of these fields. As explained in my introduction, Sandberg and Marshall interrogate restrictive discourses of generativity, which assume hetero-reproductive success and "sound" body-minds (see also Grande 2018; Kafer 2013). Signs of a good future, accordingly, include being "physically-fit, youthful-looking, financially secure, happy heterosexuals," who maintain leisurely intimacies with children and grandchildren (Sandberg \& Marshall 2017: 4).

In recent years, critical queer and disability scholars have similarly interrogated the implications of conceptualizing futurity and generativity in such limiting and discriminatory ways, also offering important insights for social gerontology. Two themes within this work are especially pertinent to this analysis. First, several scholars reveal and redress absences in recognizable futures for certain subjects, or the positioning of Others' (nonnormative) futures as failed, miserable, or non-futures (e.g. Edelman 2004; Jones 2011; Rice et al. 2017). Such analyses interrogate the ways in which overlapping systems of power create silences, omissions, and invisibilities that position queerness and disability as antithetical to futurity - that is, LGBTQ2IA+ people and people living with disabilities are viewed as having no futures, or certainly not positive ones (Kafer 2013; Shepherd 2016). These scholars clearly critique such "non-future" narratives, calling upon researchers to continue making multiple, positive, nonnormative futurities legible. Second, and related, several scholars have theorized alternative or nonnormative temporalities and ways of conceptualizing generativity, as a project of widening (rather than limiting) possibilities for positive futures. Halberstam, for instance, critiques the idea that lives lived outside of the reproductive temporalities of heteronormativity, or "outside of the conventional forward-moving 
narratives of birth, marriage, reproduction and death," are denied generativity and thus future happiness. Instead, Halberstam offers "queer time" as a concept of a life trajectory "unscripted by the convention of family, inheritance, and child-rearing" (2005: 16). Fabbre suggests that people who undergo a gender transition in later life expand "notions of queer temporality by drawing attention to growing older in ways that do not follow heteronormative scripts" (2014: 171). And, Rice et al. offer the possibilities of "feminist crip time," which involves replacing linear and static ideas about a "future perfect" with multiple, dynamic temporalities, making space for futures that "include bodies/minds left out of normative renderings of personhood and futurity" (2017: 27). Collectively, this work unpacks the normalizing workings of oppressive systems while valuing complex lives lived on the margins - with joy, pain, and diverse meanings.

Building on these important efforts at queering and cripping aging futures, an emerging finding in my own research is that even these most critical interventions tend to leave intact the ways in which colonialnormativity operates and intertwines with capitalism, ableism, and heteropatriarchy. In moving toward a project that might unsettle this colonial-normativity, I would like to briefly explore four sets of insights offered by Indigenous and decolonial scholars working outside of gerontology. These insights also help contextualize the knowledges offered through Caskanette's and Beeds' stories, which follow.

First, a multitude of writings on Indigenous futurities clearly speak to and resist the "no future" narratives that surround Indigenous communities, resonating with similar themes in queer and crip studies (e.g. Aikau 2015; Arvin et al. 2013; Belcourt \& Roberts 2016; Boissoneau 2016; Nixon 2016; sy 2016). These writings, importantly, start from an analysis of how settler colonialism is an ongoing system designed to eliminate Indigenous peoples: through assimilation, neglect, extermination, removal from land (and connected livelihood, food sovereignty, culture, spirituality), and outlawing of cultural practices. These writers also recognize colonial policies and practices, such as residential schooling and child apprehension, as intentional disruptions to Indigenous generativity and continuance, and they point to colonial legacies of violence against Indigenous women and girls, continuously upheld through racist judicial and law 
International Journal of Ageing and Later Life

enforcement processes and institutions, as material threats to Indigenous survivance (Boissoneau 2016; Women's Earth Alliance \& Native Youth Sexual Health Network n.d.). In this context, futurities, generativity, persistence, survivance, love, and even reproduction become forms of resistance to ongoing attempted elimination - what Anishinaabe scholar waseyaa'sin christine sy ${ }^{11}$ calls "persisting life" (sy 2018). Furthermore, generativity through reproduction (hetero or not) - acts of birthing, nurturing, and all other forms of Indigenous "making" - is often depicted in these writings not as upholding of heteropatriarchy, but as reclamation toward imagined futures beyond colonial violence. Anishinaabe writer Boissoneau writes: "when we dream our futures alive we actively reclaim our places in the world by directing energy towards sustaining life" (2016: no page).

Second, several important contributions reveal the ways in which marriage, monogamy, and heteronuclear family structures are colonial constructs, which have aimed to destroy Indigenous kinship networks, particularly in the North American context (Nixon 2016; Peek 2014; Simpson 2017; Tallbear 2016). Given presumptions of successful aging as connected to hetero-kinship, these analyses are critical to understanding the workings of colonial-normativity within this discourse. These scholars, in varied ways, not only point to heterokinship and the nuclear family as colonial projects, but also challenge hetero-reproductive/nuclear family ideas about generativity by suggesting that, outside of the influence of colonialism on family life, generative opportunities and responsibilities would extend to a wider collective, or an extended kinship network not based solely on reproduction - they thus also effectively queer the concept (Nixon 2016; Simpson 2017). Described another way, care for future generations would, outside of colonial-normative practices, include not only reproductive relationships (parents/grandparents), but also, and importantly, community and extended kinship groups. And, many further explain that the reclamation and practice of a decolonial form of love, relationship, and kinship in the present is a means of resurgence and making futurities beyond colonial relations (Nixon 2016; Simpson 2017). In her excellent 2016 lecture, "Making Love and Relations Beyond Settler

11 This author chooses not to capitalize her name. 
Sexualities," Dakota scholar Kim Tallbear delves into this colonial re-shaping of family structure and its embedded assumptions about intergenerational relations and responsibilities:

\begin{abstract}
It was not always so that the monogamous couple ideal reigned. [...] The Christian model of lifelong monogamous marriage was not a dominant worldview until the 19th century. [...] It took work to make monogamous marriage seem like a foregone conclusion and that people had to choose to make marriage the foundation of the new nation. [...] At the same time that monogamous marriage was solidified as ideal and central to both US and Canadian nation-building, Indigenous Peoples in these two countries were being viciously restrained, both conceptually and physically, inside colonial borders and institutions that included residential schools, churches and missions, and urban relocation programs. These were all designed to save the man and kill the Indian by cutting the Indian off from the collective, their Peoples and tribes. Part of saving Indians from their savagery meant pursuing the righteous monogamous couple-centric nuclear family co-produced with private property. [...] One hundred and fifty years after my Dakota ancestors were brought under colonial control, the unsustainable nuclear family is the most commonly idealized alternative to the tribal and extended family context in which I was raised. Prior to colonization the fundamental social unit of my people was the extended kin-group including plural marriage. [...] Throughout my growing up I was subjected by both whites and Natives ourselves to narratives of shortcoming and failure. [...] Now I see that it was not my family's so-called failures, but rather I was suffocating under the weight of the aspirational ideal of a normative middle-class nuclear family including normative coupledom period. [...] But despite colonial violence against our kin systems, we are, I think, in everyday practice, still adept at extended family. [...] Our tribal webs of kinship share with ethical non-monogamy [...] when it goes beyond individualistic discourses of freedom and sexual selfactualization to making family and community, we share with that the possibility for greater emotional, environmental, and economic sustainability in these extended kin networks.
\end{abstract}

Tallbear's words illuminate the workings of colonialism in forcing Indigenous communities into nuclear family structures that posit generativity as a heteronormative pursuit, or as about nurturing biological kin.

Third, several writers center mutuality, responsibility, and reciprocity as Indigenous protocols that inform intergenerational relationships and generativity (Grande 2018; Tallbear 2016). In doing so, these scholars call into question dominant (colonial-capitalist) ideas that dependency in old age is a sign of failure and/or limited futurity, which is indeed a point of intersection with critical gerontology. Quechua scholar Grande, for example, seeks an "Indigenous counter-narrative of aging, one that illuminates 
International Journal of Ageing and Later Life

the ways in which settler logics undermine, if not erase, relations of mutuality (e.g. relationality, reciprocity, kinship) that operate beyond the productivist logics of capital" (2018: 169). She critiques successful aging as a corporatist agenda that reifies individualism and marks success in later life as an ability to care for oneself without dependence on others. She also writes that "relations of responsibility, collectivity, mutuality, and reciprocity are foundational to Indigenous protocols and practices, giving rise to a number of important distinctions regarding life, death, and being-ness" (Grande 2018). Among these distinctions is a valuing of non-commodified care across generations and across living and spirit realms. In other words, this work calls out assumptions that success for older adults is being healthy and fit enough to independently care for themselves and to nurture future generations; these are based on colonial and capitalist ideas that commodify care and value productivity over mutuality. Instead, Grande and others value intergenerational relationships based on reciprocity, where life is nurtured across ages in all directions. As such, generativity does not depend on able-ness as it is extended to generations future and generations past.

Fourth, some Indigenous scholars are offering critiques of gerontological concepts such as the lifecourse, and in particular challenging mainstream conceptions of the lifecourse as having a linear temporality with birth and death as its end points (Anderson 2011; Grande 2018; Lawrence 2003; Tallbear 2016); such a challenge has repercussions for conceptions of aging, aging futures, and generativities. ${ }^{12}$ Grande, for instance, explains this critique as follows:

[A]cross the relatively few studies of aging within Indigenous communities a pattern of belief emerges around aging as an integral moment in the cycles of life(s), not temporally ordered along a linear lifespan. For instance, as found by Lewis's (2010) studies among Alaska Natives, the definition of elder is not based on chronological age, but rather is a designation or honor bestowed by the community; a status earned through "unspoken rules" regarding wisdom, experience, and contribution to community. (2018: 174)

${ }_{12}$ Elsewhere, Indigenous scholars, social gerontologists, and others are critiquing the idea of lives lived along linear temporalities, and indeed queering/unsettling time through discussions of futures that are not linearly contained in future time. See, for example, Peek 2014; Pierce 2016; Riach, Rumens, \& Tyler 2014; Rice et al. 2017; sy 2016. 
She elaborates that "the state of being elderly is viewed as a product of the social imaginary, not necessarily ontologically located in the body or mind" (Grande 2018). To elucidate her point, Grande then draws on Hulko et al.'s (2010) work among Secwepemc First Nations peoples wherein infants and the elderly are described as located close to each other on the medicine wheel; in this view, both infants and the elderly are considered to be close to the spirit world, which creates some physical and mental vulnerabilities (see also Anderson 2011). She asks whether such notions of elderly people as moving back towards Creator and the spiritual realm might provide a conceptual opening for, among other things, rethinking biomedical models of what it means to be of "sound mind." Such beliefs about aging could perhaps assist in the project of cripping aging futures while also extending generativity into a multidirectional nurturing of life that does not necessarily end with death.

Finally, interweaving many of these insights are important challenges to colonial (Western/Christian) ideas about animacy, which implicate ways of conceptualizing futures, responsibilities, and relations. Some scholars describe this as a colonial separation between material (living) and spiritual (ancestral) realms (Tallbear 2016), which results in colonial-normative assumptions that intergenerational relationships are fostered only among the living (i.e. typically child through to (great) grandparent). By contrast, many Indigenous perspectives on intergenerational linkages, as noted already, include spiritual connections to ancestors past and to generations yet unborn (Boissoneau 2016; Cole 2018; sy 2018). Connected to this, several Indigenous writers point to colonial assumptions of separation rather than relationality between human and nonhuman entities, which inform dominant conceptions of generativity as including only linkages to future humans, as opposed to considering generativity as also about nurturing future (and past) land, water, plants, and animals (TallBear 2016; Wall Kimmerer 2014). Unsettling these colonial assumptions has important repercussions for thinking about roles and responsibilities over much extended timeframes, outside of hetero-reproductive relationships, and beyond human relations. TallBear again offers many insights into these complexities in her 2016 lecture:

In that [Western/Christian] worldview, materiality is severed from spirit, for lack of a better word. [...] In such a worldview, spirits do not legitimately bridge worlds in 
International Journal of Ageing and Later Life

\begin{abstract}
mundane ceremonies or in dreams. [...] But [in Dakota worldview] spirits are persons, [they are] our social relations, be they wise or imperfect. Some were human, some may be again. [...] We don't pretend to know much, but we do know that death of the body opens up another stage of being, not only materially but in ways we cannot yet measure. [...] For us, materiality is part of beingness, not the other way around. Likewise, persons that are not and will never be human, those called non-human, animal, less sentient, do things in this world, and are also our relations. Just as we do not relinquish the beingness of our human relatives with the passing of their biophysical bodies, we do not relinquish our relationships with our non-human relations in these lands.
\end{abstract}

So, what becomes evident is that the project of queering and cripping aging futures critically intervenes in many normative and restrictive assumptions about "happy aging" while still leaving the colonial underpinnings within many gerontological writings unchallenged - among these the colonial/Western/Christian tendency to sever "materiality from spirit," as Tallbear explains. In seeking to extend this work, I turn now to conversations with Caskanette and Beeds, bringing their words and stories into dialogue with some of the ideas and conceptual shifts outlined here.

\title{
Elder Audrey Kewaquom-Caskanette and Tasha Beeds: Stories of survivance, generativity, and futurity
}

Both Elder Audrey Kewaquom-Caskanette and Tasha Beeds invoked themes of futurity and generativity as central to their stories. Most immediately, both spoke of being grandmothers, and thus illuminated their own biological and reproductive links to future generations. Beyond heteronormative assumptions, however, a closer listen to their stories reveals a more complex and nuanced set of understandings about intergenerational connection, aging, futurity, activisms, and their own roles and responsibilities. Critically, both storytellers challenged outright "no future" narratives (resonating with Belcourt \& Roberts 2016; Boissoneau 2016; Nixon 2016; sy 2016). In different ways, both noted the impacts of systemic colonial violence and attempts to disrupt generativity - for example, through residential schools, foster systems, and child apprehensions. Both strongly embodied continuance and survivance in the ways they discussed bearing new life, surviving into grandmotherhood, nurturing relationships with future generations within and outside of their families, connecting to community and culture, and working for Indigenous futurities. Theirs are 
stories not only of positive, meaningful aging futures, but also of creativity and resilience in persisting life (sy 2018).

Turning to Caskanette's story of her work for social change, it quickly becomes evident that she has worked in and with Indigenous-led social service organizations and around issues of youth mental health and poverty for many decades. She has also been involved in various other forms of activism, from formal protests to cultural resurgence work. She introduced herself like this:

My English name is Audrey. I come from Saugeen which is up on the Bruce Peninsula. [...] I have four children, two natural and two adopted. [...] I have grandchildren - and this is the reason I do these things - for the grandchildren, but all the grandchildren. So the students that are going to pick this up, yes that's why I am doing this. And that gives me encouragement and hope for the future and that's essentially the work that I'm about. [...] My work has come out of that beginning time and I honour my mother and father for the life that they gave and the life that we had, and why I'm here today and have survived as an Anishinaabek person.

This makes evident that, from the very start of her interview, she oriented her story toward the future, toward nurturing future generations within and outside of her own family (i.e. the reason she does the social change work she does is for "all the grandchildren"). She also recognized past generations and the roles they have played in ensuring her survival. Her generativity - her survival into old age and her connections across generations - stands in clear resistance to the workings of settler colonialism. She was clearly well aware of this.

Caskanette's story involves resisting ongoing colonial power and injustices at the hands of the state; she spoke of working to maintain the integrity of families, communities, intergenerational relationships, spirituality, and culture, in the face of colonial disruption. For instance, she told a story about supporting a new Anishinaabe mother who was left crying in the hospital just after delivering her baby. Her baby had been apprehended against her will and was being given over to a white family for adoption. The story involved Caskanette going to the courthouse, rallying others to accompany her in this, and refusing to leave until the baby was given back to the community. In defiance, she recounted: "So there I am sitting in the courthouse and the cops come and sit in front of me and said, 'now you can't stay here, this is going to be closed in five minutes.' 
International Journal of Ageing and Later Life

And I said, 'well okay, you can close up, but I'm not going anywhere, I'm not going anywhere until that baby's brought back to our community.'"

Through her storytelling, Caskanette challenged narratives of aging that link successful aging futures with capitalist and colonial aspirations. Indeed, while her story is continuously oriented around futurity, it never revealed aspirations for her own individual aging future. Never in her narrative, for example, did she allude to later life retirement, financial security, being independent, or physical fitness - even when discussing what sustains her social change work as she is aging. She recognized that certain relationships and ways of working for change were shifting as she was growing older, acknowledging bodily changes, but she did not speak about this in a negative or limiting way, and her motivation remained grounded in supporting the well-being of future generations. Her ideas about aging futures and intergenerational connection also contested notions that older adults should be independently functioning, and instead spoke of responsibility, reciprocity, and mutuality across ages (resonating with Grande 2018). She talked about her role as a "cultural grandmother," based on her age, which is a responsibility and an opportunity to continue to support and mentor youth, but also that there is a reciprocal responsibility and opportunity for future generations to support and teach her: "The cultural grandmother role helps me to work with young people. 'Cause that's the role of the grandmother. I'm connected to that young person over there because I have something to give you, and also because you have something to give me."

Finally, her ideas about generativity have a spiritual dimension, shifting beyond a Western/Christian-centric temporal framework of one lifetime and beyond relationships as limited to the living or material realm (TallBear 2016). Caskanette instead emphasized the obligations and opportunities that come from connecting to her spirit, which she understands as the basis of her generativity: it is what connects her to her future as well as her past. Connecting to spirit and assisting others to do so is also at the core of her activist work in her later life, as is evident in this passage:

The roots are so important because back there, standing behind me, are all the people from the beginning of time. [...] They're still there, the essence of them are still here, encouraging us to be as full and alive as we can. [...] My activism now, if you want to 
call it that, is to preserve the spiritual connection that everybody needs, not just Anishinaabek people. [...] I am about helping people to understand, if they come and ask, how is it that I connect to my spirit. My spirit is the thing that is going to live on after I go.

These ideas about generativity as linking to future life within but also beyond familial relationships, extending the temporal nature of generativity outside of one lifetime, and opening up generative possibilities beyond the material and into the spiritual realm reverberate through the literature discussed earlier. These themes also resonate strongly with Beeds' story.

Like Caskanette, Beeds reflected on what drew her into activism in a way that was clearly future-oriented; about working for the well-being of future generations, and about a sense of generativity that is much broader than that of mainstream gerontology (Sandberg \& Marshall 2017). She too spoke eloquently about Indigenous persistence and futurity in the face of violence against Indigenous women - this was a clear impetus for her activism. Beeds' own survival, persistence, nurturing of new life, connections across generations, and work for Indigenous futurities were all also part of her story. It is worth reiterating that hers too is a powerful counter-narrative to "no future" discourses, as is clear in the following reflection on what drew her into activism:

\footnotetext{
My work in academia would be my first area of activism, and that was looking at the cases of missing and murdered Indigenous women. A good friend of mine [...] went missing in 2004 and that was a catalyst for me to begin to realize - I mean I always knew, that there was this violence directed at us. I was cautioned as a young girl growing up in Saskatchewan that there would be people who would target me because of my brownness. But the catalyst for me was when this beautiful young woman who was intending to be a teacher, who was a mother, a wife, a daughter, friend, a sister... when she went missing, that moved me. I wanted to know why. [...] I wanted to understand how it is that Indigenous women were going missing at such an alarming rate. [...] I want to understand and create a safer space for future Indigenous girls, for Indigenous girls that exist now, for Indigenous women, for my people.
}

Her story continued with this theme of futurity, but, like Caskanette, she never delved into a discussion of her own aging future - at least not in her embodied form. She also did not depict a narrative of heterohappiness per se, or about individual financial security, retirement, or 
International Journal of Ageing and Later Life

able-bodied/able-minded independence (Grande 2018). But she did center her story around generativity - connecting to and working for future life. This generativity includes connection to her own offspring but, and perhaps more strikingly, it extends to deeply held links to her future relations, within and outside of family lines, and to entities both human and nonhuman (Tallbear 2016). This is most clearly expressed in her discussion of her work for the water and her ceremonial practice as social change work:

That work [on colonial violence] led me into ceremony because I needed something [... because] it was very heavy, heavy work. [...] I began to look at one particular obligation and responsibility and that's work for the water. [...] I began to understand how water is a living entity and how she can help us as much as we need to help her. [...] And it was through the local Anishinaabekewag [Anishinaabe women], [...] they introduced me to the practice of water walking, and from them I met Josephine Mandamin, who is the grandmother who walked around all of the Great Lakes, and then some. [...]

So I began to walk for the water and I began to enter into relationship with nibi, as she's known in this territory. [...] I understand that Elders tell us that we don't actually have much time, that there are things that are going to happen in the future that we can't even anticipate, and it is because of our neglect. [...] There are consequences that are going to play out for generations to come. [...] There is always a message of hope: if we can begin to shift out ways of being in the world, if we can remember our relatives and how we are connected to every single living entity on Earth, [...] there's a window there, but it's a closing window. [...]

Once we begin to realize those relationships, and we understand how reciprocal they are, then maybe we can start to shift. Maybe we'll start to see the water as living. Maybe we'll start to see the Earth as a living, breathing entity. [...] I think it's really important for the next generations to understand that the Earth is not a resource. The waters are not a resource. They're part of a living, breathing connection that we're all part of [...] to begin to think about how you relate to the earth, how you relate to the water, in ways that do not take away life, but sustain life, and give life.

Her words capture a conception of generativity as encompassing caring for the land and the water as living entities that will sustain future generations, ensuring that future generations have the necessary means for life. In other words, she described her responsibility and obligation to nurture the water, to ensure the water's life into the future. She views water as living and as a life-giving force for both human and nonhuman entities. 
In a more conventional gerontological sense, Beeds also spoke of generativity in relation to her own granddaughter. She highlighted the importance of her granddaughter and the experience of entering grandmotherhood as motivating her ongoing work for change. Like Caskanette, then, her story also offers a narrative of "reproductive success" (Sandberg \& Marshall 2017). But also, like Caskanette, Beeds' story and way of speaking about her passage into grandmotherhood disrupts this hetero/ colonial version of generativity (Tallbear 2016). For Beeds, the birth of her granddaughter was a call to action to work harder for the water, in ceremony and in all of her social change efforts, because it came as a reminder that she would become an ancestor: her discussion of her generative responsibilities invoked by becoming a grandmother was most clear in her reflection of how her activism has changed as she has aged:

I think one of the driving forces for me [in my activism] was becoming a grandmother, becoming a kokum. [...] I realized I wanted the world to be a better place for my granddaughter. I didn't want her to experience the pain, the trauma, and the violence that so many of my people have already. I wanted to know that there was going to be clean water for her, that the world was going to be a safe place for her. It was like all of these responsibilities and obligations fell into my heart. I knew that I had so much work to do. [...] It was a huge shift for me knowing that this little girl is going to be here long after I am gone. [...] Josephine Mandamin always says, seven generations ago your ancestors were looking at you right now, and they were saying, "How can I make this good for them? What [...] are they going to need?" And when I held that little girl in my arms, I looked into the future and I saw that I was going to be someone's ancestor. And I asked myself, what kind of ancestor do you want to be? [... I want to be] the kind of ancestor that they look back on and say, "She did everything she could. She spoke, she fought, she wrote, she walked for the water. She tried. In the face of all this violence, she kept moving." That's what I want them to say.

Her passage into grandmotherhood, in other words, made her aware of generativity encompassed within the spirit world, which bridges multiple generations of ancestors. This is clearly evident in her discussion of her relational links seven generations into the future and seven generations into the past, and the responsibilities that come from these connections.

Finally, toward the end of her interview, Beeds clarified that, in her understanding, generativity cannot be limited to reproduction or familial/kinship relationships, but is more about collectively sustaining future generations. Upon wrapping up her story, a conversation 
International Journal of Ageing and Later Life

continued around the idea of becoming an ancestor as motivating working for change. Beeds then turned to another storyteller in the room - an Indigenous woman, knowledge holder, and activist of a similar age who has worked relentlessly to change sex discrimination in Canada's Indian Act, and who happened to never have had children or grandchildren. Beeds continued:

That's the question - what kind of ancestor do you want to be? The realization that I am someone's ancestor is what drives me to work hard for those still to come. And we don't have to give birth to be an ancestor. We are all going to be ancestors. You never had children, but you are going to be an amazing ancestor - with all the work she is doing for the future generations of Indigenous girls and women, she is a powerful and positive ancestor-to-be.

This acknowledgement of this person's role in generativity, expressed through working for change for future generations outside of familial relationships, speaks to ideas about generative responsibilities as falling upon community or extended kinship groups, not as solely based in biological reproduction (Tallbear 2016).

Both stories and storytellers reveal positive and meaningful aging experiences, outside and beyond dominant notions of "happy aging futures" and "hetero-happiness," and outside the narrow success-failure dichotomy of successful aging discourse (Sandberg \& Marshall 2017). In telling their stories of working for change over their lives, both orient themselves toward the future: working for and linking to future generations is central to what they are doing as they age. But, both storytellers' perspectives on futurity and generativity also challenge the ways in which these ideas are typically understood within gerontology, even within the critical project of queering/cripping aging futures.

\section{Conclusion}

This analysis has built from my own interest in, and commitment to, critically expanding dominant understandings of both aging and activisms beyond Eurocentric, white-centric, and colonial conceptions (Chazan 2018). It also reflects my ongoing personal deliberations - as an academic, activist, and parent - around my responsibilities, relationships, and 
subjectivities as a white settler who is deeply invested in, and always uncertain about, what Carter et al. (2017) call "reworlding" - making antioppressive futures that do not reproduce or rely on colonial/capitalist power structures. I am committed to continuously exploring the complexities of my positions and the power dynamics involved because I believe that, practiced in critical and humble ways, storytelling, research, and relationship-building can all be part of making decolonial, anticapitalist, queer, crip, and feminist futures.

I have, in this article, attempted to share some of what storytellers in my research shared with me, in this spirit of reworlding. Specifically, I have drawn on the stories of two vibrant and indomitable social changers, both identifying as Indigenous grandmothers and activists, to suggest an analysis of how their knowledges might unsettle certain core gerontological concepts and ideas: aging futures, generativity, futurity, and the lifecourse, among others. As Grande so eloquently explains, and I concur, "Indigenous perspectives on aging are crucial. Not in a liberal sense of adding culturally relevant models for the sake of pluralism, but as a rupturing - a 'decolonial option' to the dehumanizing logics of capitalism and the settler state" (2018: 173). I tread with deliberate uncertainty in this work; while I am working from a place of relationship-building and toward a practice of radical listening, I am still constrained by my necessarily fraught settler relationship to the very idea of unsettling aging futures. I have, therefore, also sought to contextualize these two stories, and indeed my analysis, within the scholarship of Indigenous thinkers more broadly, particularly those whose work has yet to come into sustained dialogue with gerontology. Even though I do so, it is important for readers to bear in mind that the two stories I have shared are two among multiple and diverse perspectives that could be offered by activists from widely varied Indigenous territories and cultures across Turtle Island (North America).

What emerges, nevertheless, are two revealing stories of survivance, of "persisting life," in the words of waaseyaa'sin christine sy (2018). Caskanette's and Beeds' stories both clearly challenge "no future" narratives; they resist the ongoing attempts of settler colonialism to eliminate and assimilate. They also contest successful aging discourse in very important ways. Theirs are stories of generativity and futurity, and even 
International Journal of Ageing and Later Life

of positive aging - but none of these in conventional colonial/capitalist/ ableist/heteronormative terms. These are not, for instance, about happy individualism as they age; they are not about accumulating wealth, being independent, retiring, or nurturing their own grandchildren for the purposes of building legacy; and they are not about volunteering as a leisure activity what will keep them active or healthy. Rather, these are powerful stories of continuance - of continuing the struggle and the joy of reworlding, of continuing to honor their relations and responsibilities. Both storytellers describe their work as future-oriented, but in a collective sense: sustaining lives, sustaining land and water, sustaining spirits, across generations. They acknowledge aging bodies as having different needs and elderly people as having changing responsibilities; they speak of relationships across generations in terms of these needs and responsibilities, based on reciprocity.

Conceptually, what is so striking is their radical intervention into colonial/capitalist/heteropatriarchal notions of generativity. Both Caskanette's and Beeds' stories are about connections far into the future and the past. This begs a shift in thinking about the central idea of animacy, toward an understanding of generativity as having a basis in the spirit world. From this perspective, generativity might be considered the work of nurturing ancestors seven generations past and working for futures seven generations ahead; it might also be the work of nurturing the nonhuman world into the future, or a generativity connected to land, water, and all of creation. These ideas clearly crip and queer aging futures in very significant ways - moving generativity well outside of heterokinship relationships and beyond a requirement of medically "sound" minds and bodies.

Sandberg and Marshall "call on cultural gerontology to further problematize the dividing practices that make some futures more valued than others, and instead find ways to recognize diversity as more than a catch phrase. This calls for a radical reshaping of cultural imaginaries of aging futures" (2017: 9-10). I hope, in some preliminary ways, the stories and knowledges in this article will open difficult, indeed unsettling, conversations about what these cultural imaginaries might be and, critically, to whom scholars in gerontology might look as we stumble along in our project of imagining futurities beyond oppressive colonial, capitalist, and heteropatriarchal values. 
Unsettling aging futures

\section{Acknowledgments}

The author gratefully thanks Audrey Kewaquom-Caskanette and Tasha Beeds for sharing their knowledges with her research team and students, for their careful review of this article in its early draft form, and for their ongoing relationships. She extends thanks to all of the participants in the 2017 Stories of Resistance workshops, who collectively were part of producing the stories offered in this article, and especially to Hannah Collins, Emma Langley, and Mary Bartram-Hollingworth for taking on the roles of interviewers in the highlighted stories. Several colleagues and research assistants offered invaluable input and labor into the writing of this article: Melissa Baldwin, Jenn Cole, Barbara Marshall, Ziysah von Bieberstein, and IJAL's two anonymous reviewers. This research was funded by the Social Sciences and Humanities Research Council of Canada through the Canada Research Chairs program. It was reviewed Trent University's Research Ethics Review Board in 2017 (file 23036) and received approval in accordance with Canada's Tri-Council Guidelines for Ethical Research with Human Subjects.

\section{Corresponding Author}

May Chazan, Department of Gender and Women's Studies, Trent University, Lady Eaton College N114, 1600 West Bank Drive, Peterborough, Ontario, Canada, K9L 0G2. Email: maychazan@trentu.ca

\section{References}

Aikau, H. K. (2015). Following the Alaloa Kippapa of our ancestors: A trans-indigenous futurity without the state (United States or otherwise). American Quarterly 67(3): 653-661.

Anderson, K. (2011). Life Stages and Native Women: Memory, Teachings, and Story Medicine. Winnipeg, MB: University of Winnipeg Press.

Arvin, M., Tuck, E. \& Morill, A. (2013). Decolonizing feminism: Challenging connection between settler colonialism and heteropatriarchy. Feminist Formations 25(1): 8-34.

Belcourt, B. \& Roberts, M. (2016). Making friends for the end of the world. GUTS Magazine, FUTURES issue (Spring 2016). Available on http:/ / gutsmagazine.ca/making-friends/ (Accessed: January 9, 2019). 
International Journal of Ageing and Later Life

Boissoneau, D. (2016). Seed songs: Growing the sacred feminine, a poetic manifesto. GUTS Magazine, FUTURES issue (Spring 2016). Available on http:/ / gutsmagazine.ca/seed-songs/ (Accessed: January 9, 2019).

Braun, K. L., Browne, C. V., Ka'opua, L. S., Kim, B. J. \& Mokuau, N. (2014). Research on indigenous elders: From positivistic to decolonizing methodologies. The Gerontologist 54(1): 117-126.

Carter, J., Recollet, K. \& Robinson, D. (2017). Interventions into the maw of old world hunger: Frog monsters, kinstellatory maps, and radical relationalities in a project of reworlding. In H. David-Fisch (ed.), Canadian Performance Histories and Historiographies (pp. 205-231). Toronto, ON: Playwrights Canada Press.

Chazan, M. (2018). Introduction: Amplifying activisms. In M. Chazan, M. Baldwin \& P. Evans (eds.), Unsettling Activisms: Critical Interventions on Aging, Gender, and Social Change (pp. 1-20). Toronto, ON: Women's Press.

Cole, J. (2018). Following Nan to the Kiji Sibi. In M. Chazan, M. Baldwin \& P. Evans (eds.), Unsettling Activisms: Critical Interventions on Aging, Gender, and Social Change (pp. 229-232). Toronto, ON: Women's Press.

Cunsolo Willox, A., Harper, S. L., Edge, V. L., My Word: Storytelling and Digital media Lab, \& Rigolet Inuit Community Government. (2012). Storytelling in a digital age: Digital storytelling as an emerging narrative method for preserving and promoting indigenous oral wisdom. Qualitative Research 13: 127-147.

Edelman, L. (2004). No Future: Queer Theory and the Death Drive. Durham, NC: Duke University Press.

Erikson, E. H. (1963). Childhood and Society (2nd ed.). New York: Norton.

Fabbre, V. D. (2014). Gender transitions in later life: The significance of time in queer aging. Journal of Gerontological Social Work 57: 161-175.

Gidigaa Migizi (Williams, D.). (edited by Simpson, L. B.). (2018). Michi Saagiig Nishnaabeg: This Is Our Territory. Winnipeg, MB: ARP Books.

Grande, S. (2018). Aging, precarity, and the struggle for Indigenous elsewheres. International Journal of Qualitative Studies in Education 31(3): 168-176. https:/ / doi.org/10.1080/09518398.2017.1401145

Halberstam, J. (2005). In a Queer Time and Place: Transgender Bodies, Subcultural Lives. New York, NY: New York University Press.

Hostetler, A. J. (2009). Generativity and time in gay men's life stories. In P. L. Hammack \& B. Cohler (eds.), The Story of Sexual Identity: Narrative 
Perspectives on the Gay and Lesbian Life Course (pp. 397-424). Oxford, UK: Oxford University Press.

Hulko, W., Camille, E., Antifeau, E., Arnouse, M., Bachynski, N. \& Taylor, D. (2010). Views of first nation elders on memory loss and memory care in later life. Journal of Cross-Cultural Gerontology 25(4): 317-342.

Jones, R. L. (2011). Imagining bisexual futures: Positive, non-normative later life. Journal of Bisexuality 11: 245-270.

Kafer, A. (2013). Feminist, Queer, Crip. Bloomington, IN: Indiana University Press.

Lawrence, B. (2003). Approaching the fourth mountain: Native women and the ageing process. In K. Anderson \& B. Lawrence (eds.), Strong Women Stories: Native Vision and Community Survival (pp. 121-134). Toronto, ON: Sumach Press.

Lewis, J. P. (2010). Successful aging through the eyes of Alaska natives: Exploring generational differences among Alaska natives. Journal of Cross-Cultural Gerontology 25(4): 385-396.

Lewis, J. P. \& Allen, J. (2017). Alaska native elders in recovery: Linkages between indigenous cultural generativity and sobriety to promote successful aging. Journal of Cross-Cultural Gerontology 32: $209-222$.

Loe, M. (2013). The digital life history project: Intergenerational collaborative research. Gerontology \& Geriatrics Education 34: 26-42.

Mackey, E. (2016). Unsettled Expectations: Uncertainty, Land, and Settler Decolonization. Black Point, NB: Fernwood Publishers.

Morrow-Howell, N., Hong, S. \& Tang, F. (2009). Who benefits from volunteering? Variations in perceived benefits. The Gerontologist 49(1): 91-102.

Nixon, L. (2016). Visual culture of indigenous futurisms: sâkihitomaskihkiy acâhkosiwikamikohk. GUTS Magazine, FUTURES issue (Spring 2016). Available on http://gutsmagazine.ca/visual-cultures/ (Accessed: January 9, 2019).

Peek, M. (2014). Kinship cross-talk: Love and belonging in contemporary comparative literatures. Unpublished PhD Dissertation, McMaster University. Available on https://macsphere.mcmaster.ca/bitstream/ 11375/15411/1/Peek-Dissertation.pdf (Accessed: December 17, 2018). 
International Journal of Ageing and Later Life

Pierce, J. M. (2016). Feeling, Disrupting. Biography 39(3): 434-437.

Ranzijn, R. (2010). Active ageing - Another way to oppress marginalized and disadvantaged elders?: Aboriginal elders as a case study. Journal of Health Psychology 15(5): 716-723.

Riach, K., Rumens, N., Tyler, M. (2014). Un/doing chromonormativity: Negotiating ageing, gender and sexuality in organizational life. Organizational Studies 35(11): 1677-1698.

Rice, C., Chandler, E., Harrison, E., Liddiard, K. \& Ferrari, M. (2015). Project Re $\bullet$ Vision: Disability at the edges of representation. Disability $\mathcal{E}$ Society 30: 513-527.

Rice, C., Chandler, E., Rinaldi, J., Changfoot, N., Liddiard, K., Mykitiuk, R. \& Mündel, I. (2017). Imagining disability futurities. Hypatia 32(2): 1-17.

Sandberg, L. \& Marshall, B. M. (2017). Queering aging futures. Societies 7(3): 1-11. doi:10.3390/ soc7030021

Shepherd, L. (2016). Forgiving the future. GUTS Magazine, FUTURES issue (Spring 2016). Available on http://gutsmagazine.ca/forgivingthe-future/ (Accessed: January 9, 2019).

Simpson, L. B. (2017). As We Have Always Done: Indigenous Freedom through Radical Resistance. Minneapolis, MN: University of Minnesota Press.

Sium, A. \& Ritskes, E. (2013). Speaking truth to power: Indigenous storytelling as an act of living resistance. Decolonization: Indigeneity, Education, \& Society 2: i-x.

sy, w. c. (2016). At the boiling place: Reading sap for future Anishinaabeg sugar bush (re)matriation. GUTS Magazine, FUTURES issue (Spring 2016). Available on http://gutsmagazine.ca/boiling-place/ (Accessed: December 1, 2018).

sy, w. c. (2018). Introduction to part II: Persisting. In M. Chazan, M. Baldwin \& P. Evans (eds.), Unsettling Activisms: Critical Interventions on Aging, Gender, and Social Change (pp. 74-79). Toronto, ON: Women's Press.

Tallbear, K. (2016). Making love and relations beyond settler sexualities. Public lecture. Social Justice Institute Noted Scholars Lecture Series, University of British Colombia. Available on www.youtube.com/ watch?v=zfdo2ujRUv8\&t=2869s (Accessed: December 1, 2018).

Taylor, A. \& Dokis, M. Dirs. (2015). OSHKIGMONG: A Place Where I Belong [DVD]. Curve Lake: Curve Lake First Nation. 
Wall Kimmerer, R. (2014). Braiding Sweetgrass: Indigenous Wisdom, Scientific Knowledge, and the Teachings of Plants. Minneapolis, MN: Milkweed Press.

Warburton, J. (2014). Intergenerational programs and the promotion of generativity. Journal of Intergenerational Relationships 12(2): 213-216.

Women's Earth Alliance \& Native Youth Sexual Health Network. n.d. Violence on the Land, Violence on Our Bodies: Building an Indigenous Response to Environmental Violence. Available on www.landbodydefense.org/ uploads/files/VLVBReportToolkit2016.pdf (Accessed: December 20, 2018).

Zepeda, S. J. (2014). Queer Xicana Indígena cultural production: Remembering through oral and visual storytelling. Decolonization: Indigeneity, Education, \& Society 3: 119-141. 